\title{
EVALUATION OF SERUM URIC ACID LEVELS IN PATIENTS WITH PRIMARY THYROID DYSFUNCTION
}

\author{
Aisha Ayyub ${ }^{\mid 凶}$, Muhammad Asif Nawaz ${ }^{2}$, Muhammad Basharat Khan ${ }^{3}$
}

\begin{abstract}
OBJECTIVE: To evaluate the levels of serum uric acid in the patients with primary thyroid dysfunction

METHODS: This cross-sectional study was carried out at Military Hospital $(\mathrm{MH})$ Rawalpindi, Pakistan from July-December 2014 after obtaining the ethical and institutional permission. A total of sixty patients of both genders and newly diagnosed with primary thyroid dysfunction were recruited. Informed written consent was obtained from each participant. Patients were categorized in primary hyperthyroid (serum TSH $<0.40 \mathrm{mlU} / \mathrm{L}$ and elevated $\mathrm{fT}_{4}$ ) and primary hypothyroid (serum $\mathrm{TSH}>4.50 \mathrm{mIU} / \mathrm{L}$ and reduced $\mathrm{f}_{4}$ ) groups. Serum uric acid levels of both groups were estimated and levels $>420 \mu \mathrm{mol} / \mathrm{L}$ in males and $>360 \mu \mathrm{mol} / \mathrm{L}$ in females were labeled as hyperuricemia. Results were entered and analyzed through SPSS version 21.
\end{abstract}

RESULTS: Out of sixty participants, 21 (35\%) patients were male while 39 $(65 \%)$ patients were females and mean age was $42.31 \pm 1 \mathrm{I} .27$ years. Primary hypothyroidism group consisted of 43 (71.7\%) patients while $17(28.3 \%)$ patients were in primary hyperthyroidism group. Elevated serum uric acid levels were present in $65 \%$ patients $(n=39)$. In the patients with hypothyroidism, 3 I out of $43(72 \%)$ patients were diagnosed with hyperuricemia while the corresponding numbers in hyperthyroid group were 8 out of 17 (47\%). However, difference among mean Serum uric acid levels of both groups was insignificant (385.27 \pm I $82 \mu \mathrm{mol} / \mathrm{L}$ and $316.95 \pm 169 \mu \mathrm{mol} / \mathrm{L}, p>0.0 \mathrm{I})$.

CONCLUSION: Patients with primary thyroid dysfunction have elevated serum uric acid levels that are more frequent in primary hypothyroidism as compared to primary hyperthyroidism.

KEY WORDS: Endocrine System Diseases (MeSH); Hyperuricemia (MeSH); Hypothyroidism (MeSH); Primary Hyperthyroidism (MeSH); Thyroid Diseases (MeSH); Uric Acid (MeSH).

THIS ARTICLE MAY BE CITED AS: Ayyub A, Nawaz MA, Khan MB. Evaluation of serum uric acid levels in patients with primary thyroid dysfunction. Khyber Med Univ J 2018;10(2):86-89.

\section{INTRODUCTION}

$\square$ hyroid dysfunctions are among the commonest endocrine disorders, affecting almost 2 billion individuals worldwide. South Asian population with insufficient iodine intake is particularly affected.' Thyroid hormones including Thyroid stimulating hormone (TSH), triiodothyronine $\left(\mathrm{T}_{3}\right)$ and free thyroxine $\left(\mathrm{fT}_{4}\right)$, being essential for the optimal functioning of almost all body tissues, play a critical role in growth, cell differentiation and cellular metabolism. ${ }^{2}$ Therefore, their abnormal production results in various biochemical abnormalities leading to increased risk of metabolic syndrome, cardiovascular and musculoskeletal disorders. ${ }^{3}$

Thyroid dysfunction also affects the purine nucleotide metabolism that may increase uric acid concentration which is the end-product of purine metabolism and is a primary risk factor for development of gout. ${ }^{4}$ Similar to thyroid dysfunction, the increased serum uric acid (SUA) levels are also associated with other co-morbid conditions including hypertension,
$I^{凶}$ Assistant Professor, Department of Pathology, Khyber Medical University Institute of Medical Sciences, (KIMS), Kohat, Pakistan

Cell \# +92-333-395241 7

Email:draishaayyub@gmail.com

2 Head of Department Chemical Pathology \& Endocrinology, Armed Forces Institute of Pathology (AFIP), Rawalpindi, Pakistan

3 Assistant Professor Pathology, Abbottabad International Medical College, Abbottabad, Pakistan

Date Submitted: October 15, 2017

Date Revised: June 02,2018

Date Accepted: June 08,2018

metabolic syndrome, chronic kidney disease and type 2 diabetes mellitus. ${ }^{5,6}$ The National Health and Nutrition Examination Survey also reported that the elevated SUA levels are independently and significantly associated with higher risk of cardiovascular mortality ${ }^{7}$ as the thyroid dysfunction and SUA concentration both have a negative impact on human health.

Previous studies have tried to explore the link between these two conditions as thyroid dysfunction alters the uric acid concentration also along with other metabolic derangments. ${ }^{8-12}$ Few researchers suggested that both, the elevation as well as reduction in SUA levels were attributed to increased rate of purine metabolism in primary hyperthyroidism and decreased renal perfusion and glomerular filtration rate (GFR) in primary hypothyroid patients. ${ }^{13}$ However, the results of such studies were inconsistent and the relationship between thyroid dysfunction and SUA concentrations is still unclear.

The concurrence of deranged SUA levels in patients suffering from primary thyroid dysfunction may not only increase the risk of all-cause mortality but can also affect the management and prognosis of the disease. ${ }^{6,14}$ Local literature on this issue is very limited and we designed this cross sectional study to evaluate the levels of SUA in patients suffering from primary thyroid dysfunction in our setup.

\section{METHODS}

This cross-sectional study was carried out at Military Hospital (MH) Rawalpindi, Pakistan, from July 2014 to 
TABLE I: BASELINE CHARACTERISTICS OF PATIENTS WITH PRIMARY THYROID DYSFUNCTION (N=60)

\begin{tabular}{|l|c|c|c|}
\hline \multicolumn{2}{|c|}{$\begin{array}{c}\text { Characteristics of study Participants } \\
(\mathbf{n}=\mathbf{6 0})\end{array}$} & $\begin{array}{c}\text { Primary Hypothyroidism } \\
(\mathbf{n}=\mathbf{4 3})\end{array}$ & $\begin{array}{c}\text { Primary Hyperthyroidism } \\
(\mathbf{n}=17)\end{array}$ \\
\hline \multirow{2}{*}{ Gender distribution } & Males & 15 & 6 \\
\cline { 2 - 4 } & Females & 28 & $1 \mathrm{I}$ \\
\hline Mean serum Thyroid Stimulating Hormone levels $(\mathrm{mlU} / \mathrm{L})$ & $15.23 \pm 11.4$ & $1.89 \pm 0.69$ \\
\hline Mean Serum Uric Acid levels $(\mu \mathrm{mol} / \mathrm{L})$ & $385.27 \pm 182 \mu \mathrm{mol} / \mathrm{L}^{*}$ & $316.95 \pm 169 \mu \mathrm{mol} / \mathrm{L}^{*}$ \\
\hline
\end{tabular}

p $>0.0$ I on Independent Sample t-test

December 2014 after obtaining the ethical and institutional permission. A total of sixty patients, both males and females newly diagnosed with primary thyroid dysfunction were recruited through non-probability purposive sampling and informed written consent was obtained from each participant. Exclusion criteria include the history of any other endocrine disorder, hepatic disease, renal disease and medicines which can affect the serum uric acid and thyroid hormone levels.

After obtaining the detailed medical history, basal blood specimen was collected under aseptic conditions. Serum $\mathrm{TSH}$, total $\mathrm{T}_{3}$ and $\mathrm{fT}_{4}$ levels were measured through Chemilumines-cence immunoassay. On the basis of measured levels of serum $\mathrm{TSH}$ and $\mathrm{fT}_{4}$, study participants were then categorized in primary hyperthyroid (serum TSH $<0.40 \mathrm{mIU} / \mathrm{L}$ and elevated $\mathrm{fT}_{4}$ ) and primary hypothyroid (serum TSH $>4.50 \mathrm{mlU} / \mathrm{L}$ and reduced $\mathrm{fT}_{4}$ ) groups. SUA levels of both group were determined through standard method using chemistry autoanalyzer and hyperuricemia was defined as SUA levels $>420 \mu \mathrm{mol} / \mathrm{L}$ in males and $>360$ $\mu \mathrm{mol} / \mathrm{L}$ in females. ${ }^{15}$

Results were entered and analyzed through SPSS version 21. Mean and standard deviation were calculated for quantitative variables while frequency and percentage were calculated for qualitative variables. $p$ value $<0.0$ I was considered to be statistically significant.

\section{RESULTS}

Out of total sixty participants, 2 I (35\%) patients were male while $39(65 \%)$ patients were female with mean age of $42.31 \pm 11.27$ years. Primary thyroid dysfunction was further categorized into primary hypothyroidism and primary hyperthyroidism as shown in Table I.
Elevated serum uric acid levels were present in $65 \%$ patients $(n=39)$. In the patients with hypothyroidism, 3 I out of 43 patients $(72 \%)$ were diagnosed with hyperuricemia while the corresponding numbers in hyperthyroid group were 8 out of 17 (47\%). On the other hand, mean serum uric acid levels were not significantly different between the two groups; $385.27 \pm 182 \mu \mathrm{mol} / \mathrm{L}$ vs $316.95 \pm 169 \mu \mathrm{mol} / \mathrm{L}$ for the hypothyroid and hyperthyroid groups respectively. The frequency distribution of hyperuricemia in primary hypothyroid patients and primary hyperthyroid patients is shown in Figure I.

\section{DISCUSSION}

Primary thyroid dysfunction is one of the most common endocrine disorders that results in various biochemical abnormalities including altered purine metabolism and deranged SUA levels. ${ }^{16}$ Both disorders are associated with other co-morbid conditions such as

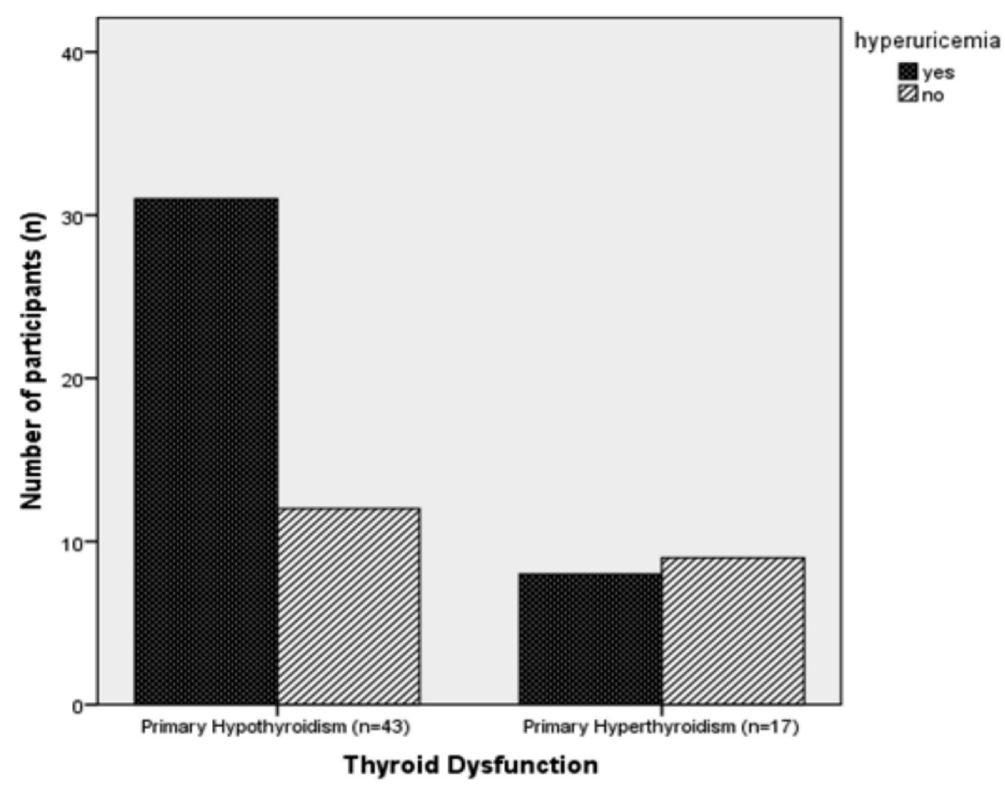

Figure I: Frequency Distribution of Hyperuricemia in patients with Primary Hypothyroidism and Primary Hyperthyroidism metabolic syndrome and cardiovascular disease. As previous studies have reported contradictory findings while exploring the link between both disorders, ${ }^{8-12}$ this study was, therefore; designed to evaluate the SUA levels in patients suffering from primary thyroid dysfunction in our setup. In the present cross-sectional study, majority of patients were suffering from primary hypothyroidism with mean serum TSH level of $15.23 \pm 11.4 \mathrm{mlU} / \mathrm{L}$. Elevated SUA levels were observed in $65 \%$ of patients affected from primary thyroid dysfunction. Furthermore, mean SUA levels of hypothyroid patients were higher than the mean SUA levels of primary hyperthyroid patients but the difference was insignificant. Hyperuricemia was also more frequent $(72 \%)$ in hypothyroid patients as compared to primary hyperthyroid patients.

Results of Giordano N, et al. ${ }^{8}$, Yakogoshi Y, et al. ${ }^{17}$, and Khan MAH, et al. ${ }^{18}$ studies are in agreement with our results as all 
of these researchers found elevated SUA levels in patients with thyroid dysfunction. See LC, et $a l^{12}$ also investigated the risk of hyperuricemia associted with thyroid dysfunction in a prospective study and found that both hypothyroid and hyperthyroid patients have elevated SUA levels, however, consistent with our findings, the difference between both groups was insignificant.

On the contrary, an African study demonstrated the lower SUA level in both, hypothyroid as well as hyperthyroid patients. ${ }^{19}$ Similarly, a large screening study that determined the SUA of 2359 consecutive patients suffering from various degrees of thyroid dysfunction including hypothyroidism and hyperthyroidism, could not find any association between SUA and TSH and therefore did not warrant routine estimation of SUA levels in such patients." The disgreement between these findings and our study results can be explained through differences in sample size and study population of these studies.

Mean SUA levels in our study were higher in hypothyroid group participant as compared to hyperthyoid patients. This finding is consistent with the previous studies. ${ }^{8,18,20,21}$ that claimed higher SUA levels in primary hyperthyroidism not more than the primary hypothyroidism patients. An indian study also reported elevated SUA levels in $35 \%$ patients of thyroid dysfunction among which $23 \%$ were hypothyroid while $12 \%$ were hyperthyroid patients. ${ }^{22}$ Although, these results were much lower than our findings where $65 \%$ patients had elevated SUA levels, higher \% distribution of hyperuricemia among hypothyroid patients is in agreement with our study findings. As elevated SUA levels in hypothyroid patients are attributed to reduced renal perfusion and impaired GFR, such patients should also be monitored closely for chronic kidney disease in additon to gout and coronary artery disease.

Our study has certain limitations also. Being a single centered, cross sectional study, its findings can not be generalised for our population. Moreover, we did not followup the study participants for development of any clinical menifestaions. Therefore; keeping in view the clinical importance of primary thyroid dysfunction, future prospective multicentre studies must be carried out at national level.

\section{CONCLUSION}

Patients with primary thyroid dysfunction have elevated serum uric acid levels that are more frequent in primary hypothyroidism as compared to primary hyperthyroidism. The elevated SUA levels in such patients not only increase the risk of other comorbid conditions but can also affect the management and prognosis of the disease.

\section{REFERENCES}

I. Zimmermann MB, Jooste PL, Pandav CS. lodine-deficiency disorders. Lancet 2008 Oct 4;372(9645): | 25|-62. DOI: 10.1016/S0I40-6736(08)61005-3.

2. Bassett JH, Williams GR. Role of thyroid hormones in skeletal development and bone maintenance. Endocr Rev 20।6;37(2): | 35-87. DOI: 10.1210/er.2015-1106.

3. Duntas LH, Brenta G. The effect of thyroid disorders on lipid levels and metabolism. Med Clin North Am 20I2;96(2):269-8I. DOI: 10.1016/j.mcna.2012.01.012.

4. Rodrigues SL, Baldo MP, Capingana P, Magalhães P, Dantas EM, Molina Mdel C, et al. Gender distribution of serum uric acid and cardiovascular risk factors: population based study. Arq Bras Cardiol 20 I 2;98(I): I3-2I .

5. Abeles AM. Hyperuricemia, gout, and cardiovascular disease: an update. Curr Rheumatol Rep $2015 ; 17(3): 13$. DOI: |0.|007/s | |926-0|5-0495-2.

6. Ahsan N, Zuberi NA, Alam SM, Effendi JS, Tunio SA. Association of high serum uric acid with risk factors of cardiovascular disease in the rheumatology clinic of a tertiary care hospital of Karachi. Ann Abbasi Shaheed Hosp Karachi Med Dent Coll 20I4; I9(I): 10-4.

7. Fang J, Alderman $\mathrm{MH}$. Serum uric acid and cardiovascular mortality the NHANES I epidemiologic follow-up study, 197I-1992. National Health and Nutrition Examination Survey. JAMA 2000;283(I8):2404- 10.

8. Giordano N, Santacroce C, Mattii G, Geraci S, Amendola A, Gennari C. Hyperuricemia and gout in thyroid endocrine disorders. Clin Exp Rheumatol 200 I; I 9(6):66 I-5

9. Zhang J, Meng Z, Zhang Q, Liu L, Song K, Tan J, et al. Gender impact on the correlations between subclinical thyroid dysfunction and hyperuricemia in Chinese. Clin Rheumatol 2016;35(I): 143-9. DOI: I0.1007/s |0067-0|5-2867-4.

I0. Ye Y, Gai X, Xie H, Jiao L, Zhang S. Association between serum free thyroxine (FT4) and uric acid levels in populations without overt thyroid dysfunction. Ann Clin Lab Sci 2015;45(I):49-53

I I. Raber W, Vukovich T, Vierhapper H. Serum uric acid concentration and thyroid-stimulating-hormone (TSH): results of screening for hyperuricaemia in 2359 consecutive patients with various degrees of thyroid dysfunction. Wien Klin Wochenschr 1999; I I I(8):326-8

12. See LC, Kuo CF, Yu KH, Luo SF, Chou IJ, Ko YS, et al. Hyperthyroid and hypothyroid status was strongly associated with gout and weakly associated with hyperuricaemia. PloS One 2014;9(I2):el|4579. DOI: I0.137I/journal.pone. 0114579 .

13. Khan $A H$, Majumder I. Serum creatinine and uric acid levels of hypothyroid patients. Bangladesh J Med Biochem 20 I 3;3(2):6 I-63.

14. de Oliveira EP, Burini RC. High plasma uric acid concentration: causes and consequences. Diabetol Metab Syndr 2012;4(4):4- I2. DOI: 10.1 | 86/ | 758-5996-4-12

15. Doghramji PP, Wortmann RL. Hyperuricemia and gout: new concepts in diagnosis and management. Postgrad Med 2012;। 24(6):98-109. DOI: I0.3810/pgm.2012.11.2616 
16. Wedaatalla MA, Abdella AM. Assessment of plasma Uric acid Level among Sudanese Female with Thyroid Dysfunction. Sudan J Public Health 20 I 2;7(3):89-92.

17. Yokogoshi Y, Saito S. Abnormal serum uric acid level in endocrine disorders. Nihon Rinsho 1996;54(I2):3360-3

18. Khan MAH, Majumder MI, Hoque MM, Fariduddin M, Mollah FH, Arslan I. Serum Creatinine and Uric Acid Levels in Hypothyroid Patients:
A Cross Sectional Study. J Enam Med Coll 20 I 3;3(2):84-7

19. Abebe N, Kebede T, Wolde M. Assessment of renal function and electrolytes in patients with thyroid dysfunction in Addis Ababa, Ethiopia: a cross sectional study. Pan Afr Med J 2016;24:338. DOI: I0.I I604/pamj.2016.24.338.8455.

20. Sidhu GK, Malek RR, Khubchandani A, Mansuri SH, Patel MS, Oza RH. A study of serum urea, creatinine and uric acid levels in hypothyroid patients. Int J Res Med 20 I6;5(2): I I 5-8.
2I. Dariyerli N, Andican G, Catakoglu $A B$, Hatemi H, Burcak G. Hyperuricemia in hypothyroidism: is it associated with post-insulin infusion glycemic response? Tohoku J Exp Med 2003; | 99(2):59-68.

22. Tayal D, Chawla R, Arora S, Gupta VK, Sohi JS, Mallika V. Dynamic changes in biochemical markers of renal function with thyroid status-A study in Indian population. Internet J Med Update 2009;4(2):36-4I. DOI: I0.43 |4/ijmu.v4i2.43842

\section{AUTHOR'S CONTRIBUTION}

Following authors have made substantial contributions to the manuscript as under:

AA: Concept, study design, acquisition, analysis \& interpretation of data, drafting the manuscript, final approval of the version to be published

MAN: Analysis \& interpretation of data, drafting the manuscript, critical revision, final approval of the version to be published

MBK: Acquisition of data, drafting the manuscript, final approval of the version to be published

Authors agree to be accountable for all aspects of the work in ensuring that questions related to the accuracy or integrity of any part of the work are appropriately investigated and resolved.

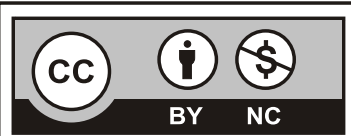

This is an Open Access article distributed under the terms of the Creative Commons Attribution-NonCommercial 2.0 Generic License.
KMUJ web address: www.kmuj.kmu.edu.pk

Email address: kmuj@kmu.edu.pk 